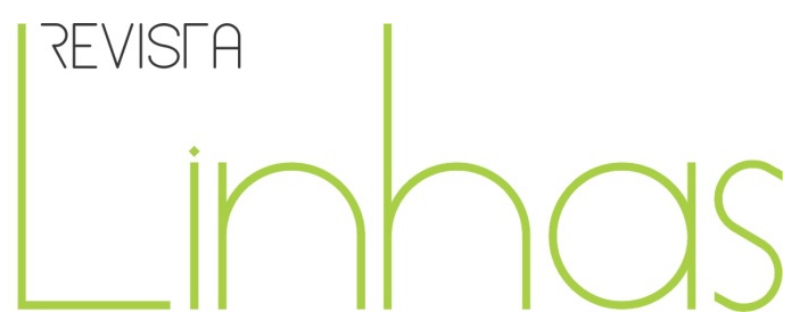

\title{
Processos sociocognitivos nos contextos de aprendizagem com o laptop educacional: um estudo de caso
}

\begin{abstract}
Resumo
Este artigo apresenta um estudo de caso que investiga os processos sociocognitivos de estudantes em interação com o laptop educacional. Os estudantes, com idade de 13 anos, frequentavam o sétimo ano do Ensino Fundamental de uma escola pública municipal, participante da etapa dois do projeto Um computador por aluno (UCA) do governo federal. Esse estudo buscou compreender os processos sociocognitivos presentes nas trocas interindividuais dos estudantes nos diferentes contextos de aprendizagem em que faziam uso do laptop educacional na disciplina de História. Para a análise de tais e nesse contexto, foi utilizado o referencial piagetiano. Com base na organização dos dados, as categorias de análise foram aprendizagem e mecanismos sociocognitivos. Concluímos que as possibilidades da interface física e digital, considerando a mobilidade do laptop na modalidade 1:1, podem configurar novas relações e desafios no processo de ensino e aprendizagem. Com relação aos processos sociocognitivos, evidenciamos uma tendência de relações de conformismo e de coação nas trocas interindividuais e um falso equilíbrio de cooperação.
\end{abstract}

Palavras-chave: Laptop educacional. Trocas interindividuais.

Processos sociocognitivos. Cultura digital.
Dirce Meri de Rossi Garcia Rafaelli

Mestre em Educação pela

Universidade de

Caxias do Sul-UCS.

dirce.garcia.rigoni@gmail.com

\section{Carla Beatris Valentini}

Doutora em Informática na

Educação pela Universidade

Federal do Rio

Grande do Sul - UFRGS.

carlabeam@gmail.com

\section{Para citar este artigo:}

RAFAELLI, Dirce Meri de Rossi Garcia; VALENTINI, Carla Beatris. Processos sociocognitivos nos contextos de aprendizagem com o laptop educacional: um estudo de caso. Revista Linhas, Florianópolis,, n. v. 14, n. 27, jul./dez. 2013. p. $134-157$.

DOI: $10.5965 / 1984723814272013134$

http://dx.doi.org/10.5965/1984723814272013134 


\title{
Socio-cognitive processes in learning contexts with laptop education: a case study
}

\begin{abstract}
This article presents a case study that investigates the social cognitive processes of students interacting with the educational laptop. Students in the age of 13 years old, in seventh grade of an elementary public school, that participates in second level of the Federal Government project Um computador por aluno (UCA). This study attempted to understand the present sociocognitive processes in the interindividual exchanges of students in different learning contexts that made use of education laptop in the history subject. For the analysis of such and in this context,, we used the Piaget theory. Based on data organization, the categories of analysis were the learning and social cognitive processes. We conclude that the possibilities of physical and digital interface in Learning Contexts, considering the mobility of the laptop in mode 1:1, can set up new relationships and challenges in the teaching and learning. Regarding the socio-cognitive processes, we noted a trend of conformity relations and coercion in exchanges interindividual and a false balance of cooperation.
\end{abstract}

Keywords: Education Laptop. Interindividual exchanges. Socio-cognitive processes. Digital culture. 


\section{O cenário da cultura digital e o contexto escolar}

A cultura digital e o mundo tecnológico provocam novas formas de comunicação, de aprendizado, de interação, de ser e estar no mundo, estando presente nos mais diversos setores do mundo contemporâneo e sendo por eles incorporados. Nos contextos educativos, esse movimento não parece tão tranquilo e natural. As instituições educacionais estão sendo provocadas para a transformação, mas essa não deve ser entendida apenas como adequação às novas tecnologias, mas a uma nova sociedade e a novos aprendizes, que parecem não mais se sujeitar aos regimes de autoridade e heteronomia em relação aos processos de aprendizagem e socialização. Aliadas a esses desafios estão as aprendizagens fundamentais apontadas no relatório da Comissão Internacional sobre a Educação para o Século XXI, coordenado por Jacques Delors para a Unesco: aprender a ser, aprender a conviver, aprender a fazer e aprender a conhecer (DELORS, 1999), evidenciando o que uma criança ou cidadão necessita aprender no contexto deste século.

Neste sentido, as inovações tecnológicas nos contextos educativos necessitam de compressão epistemológica, pedagógica e social, pois não basta a incorporação das tecnologias como meras ferramentas adicionais ou complementares às práticas tradicionais de ensinar e aprender. As inovações não se dão por inserção da tecnologia na escola, mas pela inclusão da escola na cultura digital, considerando todas as implicações que esse processo contempla, ou seja, relações autônomas, autoria, cooperação, comunicação em rede, reconfiguração de papéis. A escola, por isso, passa a se constituir mais como laboratório de investigação e cada vez menos como auditório de transmissão de informações (BECKER, 2008).

Estudos sobre o uso de tecnologias digitais na educação em diferentes países evidenciaram que essas experiências desencadearam tensões, conflitos e desafios nas relações em sala de aula e na escola (ALMEIDA, 2011). As situações conflitantes podem ser

analisadas sob a perspectiva dos sujeitos de aprendizagem. Em geral, os jovens se apropriam das tecnologias e convivem harmonicamente com a cultura digital. Este é um elemento que integra seu cotidiano fora das paredes da escola, e eles convivem com o 
universo digital de modo mais confortável que os educadores (professores, gestores, especialistas em educação), que ainda se mostram inseguros em relação a esse ambiente ou demonstram pouco interesse em incorporá-lo ao cotidiano da sala de aula.

As escolas públicas brasileiras estão vivendo um momento de intensificação da tensão, quando as políticas públicas fortalecem a necessidade de a escola assumir a atribuição da inclusão digital. Diversos projetos e programas governamentais ${ }^{1}$ desde a década de 1980 vêm promovendo ações neste sentido, com a implantação de laboratórios de informática e formação de professores. No decorrer dos anos e com os avanços tecnológicos, principalmente das tecnologias digitais em rede, o foco passou a se colocar na apropriação tecnológica. Um grande número de escolas públicas brasileiras conta com acesso à internet e a diferentes tecnologias digitais. Mais recentemente, o Programa Nacional de Informática na Educação (Proinfo) incrementa sua atuação junto às escolas públicas do Ensino Fundamental brasileiro, através da implantação, em 300 escolas do País, do projeto Um computador por aluno (UCA).

Este artigo apresenta alguns resultados de um estudo cujo objetivo foi compreender como se manifestam os processos sociocognitivos dos estudantes durante as trocas interindividuais que realizam nas diferentes situações de aprendizagem, em que faziam uso do laptop educacional.

Com o laptop educacional, as novas possibilidades de comunicação e interação podem permitir que o ato educativo seja beneficiado com a integração de outros espaços de aprendizagem, cooperação e produção de conhecimento. No entanto, sua presença na escola, na modalidade 1:1, não garante que o ensino transmissivo, descontextualizado e hierárquico abandone o contexto escolar. Um dos caminhos para transformação e inovação é o uso significativo das tecnologias digitais em que o sujeito e o grupo, ao se apropriarem das tecnologias digitais com seus recursos de comunicação e interação, desenvolvam cooperação, favorecendo o progresso da autonomia e a tomada de

\footnotetext{
${ }^{1}$ Projeto Educom, Proinfo e Proinfo Integrado, Programa Banda Larga nas Escolas, Prouca, dentre outros, são exemplos de projetos e programas de âmbito nacional que envolviam desde a captação e distribuição de recursos para a criação de laboratórios de informática nas escolas e conectividade à internet até a realização de cursos de capacitação de professores para o uso aplicado das tecnologias digitais na educação.
} 
decisão. Além disso, a presença do laptop nas mãos de cada criança facilita a mobilidade, tendo o acesso facilitado à informação pelo acesso à internet, e oportuniza a independência, uma vez que cada um tem sua máquina, o que pode provocar desestabilizações na estrutura tradicional da organização da sala de aula e do aprender.

A presença desse novo elemento no ambiente de aprendizagem, além de provocar deslocamentos e questionamentos sobre como aprender e ensinar pode, também, provocar inquietação sobre o interagir e o cooperar. Ao introduzir esse novo instrumento na sala de aula ele é legitimado como recurso pedagógico e não mais como algo estrangeiro ao espaço escolar. Com isso, permite-se que vários movimentos possam acontecer, como, por exemplo, o estudante se adaptar mais facilmente ao seu uso do que o professor. Em que outro momento da história da escola o estudante sabia mais do recurso educacional do que o professor? Isto pode provocar um deslocamento nas relações de saber e poder. Com a inserção do laptop na escola, outros sujeitos do saber começam a aparecer, ou seja, o estudante também pode ensinar e o professor também pode aprender.

Ao considerar a mobilidade que se apresenta com o laptop educacional, bem como as possíveis intervenções dos professores e as negociações em sala de aula com os estudantes, poderemos observar se essas intervenções podem se constituir como ações propulsoras do prolongamento da heteronomia, ou se poderão desencadear situações que resultarão em práticas de cooperação moral e intelectual. Tais práticas, por sua vez, poderão favorecer a ruptura ou não da superproteção e da coação, numa perspectiva de movimentar o processo de adaptação do sujeito nesse novo mundo que se descortina, favorecendo a conquista de espaços e da própria identidade, proporcionando o caminho à autonomia intelectual e moral.

\section{O cenário da epistemologia genética}

Ao estudar o movimento da cultura digital na sociedade contemporânea, em especial sobre como os artefatos tecnológicos contribuem para o exercício da cooperação entre crianças e jovens e sobre como mecanismos sociocognitivos se 
manifestam na cultura da escola, encontramos, na teoria da epistemologia genética de Piaget, o aporte teórico esta investigação.

Os estudos piagetianos fundamentam-se uma concepção de aprendizagem pautada na ação e interação do sujeito no mundo e com outros sujeitos. De acordo com Valentini (2005), o desenvolvimento do pensamento supõe condutas interindividuais a respeito dos objetos representados. Piaget (1973) considera dois tipos de trocas: a intraindividual (sujeito - objeto do conhecimento) e interindividual (sujeito - sujeito). É durante as trocas interindividuais que o olhar de Piaget se volta para a interação do sujeito na relação com o outro, inferindo que ocorre uma relação dialética na qual não existem limites que separam o social e o individual. Embora a compreensão da abordagem piagetiana para o aprender seja fundamental, o foco do presente estudo está na troca interindividual.

Piaget (1973) não considera o sujeito fora da relação social, porque é por meio da relação do sujeito com o mundo que se possibilita a construção do conhecimento. Com esse olhar, o objeto não passa a ser desvinculado do sujeito ${ }^{2}$ epistêmico ${ }^{3}$, mas é por meio do sistema de significação que ele assume novas aprendizagens, num constante movimento de pensar e agir sobre o objeto ou mesmo na relação com os seus pares, por vezes provocando desequilíbrios que favorecem a aprendizagem e, assim, acionam a rede de significados, numa ação reflexionante.

Piaget (1973), por meio de seus estudos, demonstra que o sujeito só aprende apropriando-se do que ele faz e não com o que ele repete; ainda mais quando repete algo por imposição, sem ter compreendido. Por conseguinte, a ação do sujeito da aprendizagem é determinante para o conhecer e, em especial, para o aprender. Percebemos que a escola tem muito a aprender e a mudar. O fundamental, diante da teoria epistemológica da aprendizagem, está na premissa de que não se aprende porque se repete, mas repete-se porque se aprendeu. Em outras palavras, a repetição só é

\footnotetext{
${ }^{2}$ Segundo Becker (2003), "sujeito" é um termo de tamanha complexidade. É resultado das trocas com outros sujeitos e/ou objetos, e, na medida em que conhece e descentra, consegue compreender-se como objeto entre tantos outros objetos, como um ser na sociedade humana. Ele se constitui na própria ação.

3Piaget $(1973,1977)$ chama de "sujeito epistêmico" ou "sujeito do conhecimento" aquele que é sujeito pensante.
} 
legítima quando se compreendeu um conteúdo qualquer. Nessa perspectiva, a escola continua cometendo o equívoco de achar que a repetição, por si só, produz aprendizagem, mesmo quando se repete algo que não se compreendeu.

Por outro lado, a aprendizagem escolar deveria visar ao aumento da capacidade de aprender, tão importante nos dias atuais, para além do mero acúmulo de conteúdos. A aprendizagem, na concepção piagetiana, emerge do fato de que ensinar passa a ser o aprender, e o aprender torna-se um processo de inventar.

Por isso, o professor aprende ao organizar situações de ensino e, quando reflete sobre o aprendido e como foi aprendido, pode inventar ou reinventar seus movimentos docentes. De acordo com Piaget (1998), inventar não é mera cópia, mas um processo de interação com a rede de significação dos envolvidos nesse ato - estudantes e professores.

É por meio da interação que se descobrem novos caminhos e se utiliza a capacidade inventiva e imaginativa do sujeito epistêmico, que aprende na troca e passa a ser, dessa forma, o ensinante e o aprendente, numa desvinculação de papéis, num processo de horizontalização do saber e num ato cooperativo. Assim, para que o sujeito avance no processo de aprendizagem e nos níveis de interação, a epistemologia de Piaget apresenta uma concepção de construção do conhecimento, com a qual reforça que o sujeito é que constrói e reconstrói o conhecimento.

Ainda de acordo com o autor, a cooperação é identificada como um processo em ação em que "cooperar na ação é operar em comum, isto é, ajustar por meio de novas operações (qualitativas ou métricas) de correspondência, reciprocidade ou complementaridade, as ações executadas por cada um dos parceiros" (PIAGET, 1973, p. 105).

A cooperação caracteriza-se, então, pela coordenação de pontos de vista diferentes, pelas operações de correspondência, reciprocidade ou complementaridade e pela existência de regras autônomas de conduta, fundamentadas no respeito mútuo. $O$ movimento de cooperar é único e individualizado, porque decorre da acomodação das experiências e concepções preexistentes do sujeito. Esse processo demanda uma 
reorganização da forma de pensar e conceber a realidade, propiciada por uma imposição de uma situação-problema, vivida pelo grupo, por meio das coordenações dos diferentes pontos de vista.

Ao abordar a cooperação no contexto da autonomia, o sujeito está situado no coletivo social, no qual realiza as trocas interindividuais necessárias à construção de suas possíveis hipóteses de conhecimento. No mesmo contexto, o sujeito construirá as regras e valores de convivência social, ocasionada pela necessidade de sentir-se junto ao outro ou de estar junto com o outro. Nessa dinâmica, nascem os conflitos de pontos de vista e de interesses individuais, ao mesmo tempo em que se desenvolvem o conhecimento mútuo, a confiança e o bem-querer, que unem o grupo na direção do aprender. Apesar de submetida às regras acordadas, a autonomia se evidencia na relação entre os sujeitos. Isso porque ocorre a participação do grupo no processo de criação das normas, que condiciona o grupo a optar, voluntariamente, por elas, a fim de não perder a estima dos colegas, e pelo desejo de fortalecer as relações de afeto. Essas características estão fortemente presentes na realidade dos grupos e tribos que circulam pela cultura digital e pelas escolas e demonstram uma necessidade de pertencimento ao grupo e ao meio.

Na verdade, o respeito mútuo que existe no grupo permite um exercício de autoridade de uns sobre os outros, com base na reciprocidade. Piaget (1994, p. 67) constata que "o respeito mútuo é também, portanto, fonte de obrigações, mas origina um novo tipo de obrigações que não mais impõem propriamente regras preestabelecidas: o próprio método propicia a sua elaboração." Assim, entende que os fatos mentais são paralelos aos fatos sociais, sendo o "eu" substituído pelo "nós"; as "ações" e "operações" tornam-se "interações" ou formas de "cooperação". A dimensão coletiva permite que as interações se modifiquem umas às outras, em busca de uma ação coordenada, gerando a cooperação que pode ser encontrada na relação entre os sujeitos da pesquisa, por meio da descentração, isto é, deixando o seu ponto de vista a fim de conseguir perceber o ponto de vista do outro.

Piaget $(1973,1977)$ admite que, em certas situações, as relações são cooperativas, quando o respeito ao outro se manifesta pelo conhecimento da sua própria natureza interior. Isso, para ele (1977, p. 318), se reflete na condição de uma "consciência do eu 
individual [que] é, pois, por um lado, um produto e uma condição da cooperação", visto que nas relações cooperativas o respeito é interno, ou seja, surge na medida em que o sujeito pode escolher e decidir cooperativa e voluntariamente com os outros e construir seu próprio sistema moral.

Por outro lado, na medida em que não lhe é permitido decidir e escolher, não poderá senão seguir a vontade dos outros. É nesse aspecto que o respeito ao outro implica a superação do seu ponto de vista, compartilhando com o outro uma nova escala de valores e ações, que implica também a aceitação do argumento e contra-argumento do outro, favorecendo, dessa forma, o processo dialógico.

As ações de um sujeito não são absolutamente individualizadas, mas pressupõem o intercâmbio e a colaboração com o outro, conforme Piaget (1977). Em outras palavras, a formação real da inteligência requer a convivência coletiva ativa de trocas e discussões em comum.

Piaget (1998) e Morin (2001) assinalam que a função da escola deverá ser a educação para o desenvolvimento da autonomia. Para Rangel (1992), a autonomia é a meta, é a finalidade da educação, é o que torna legítimo um ato autônomo, porque são relações de reciprocidade explicitadas em sujeitos que se respeitam mutuamente.

Neste sentido, a escola deveria envolver, em sua prática educativa, a substituição do individualismo pelas relações de solidariedade, de operar junto com o outro, exercitando descentrações e coordenando pontos de vista para chegar a acordos e a um novo entendimento da realidade, de modo a envolver a todos nesse processo de cooperação (PIAGET, 1998).

\section{O método}

A inserção dos laptops na sala de aula, no modelo 1:1, pode movimentar os processos de ensinar e aprender e as interações entre professores e estudantes. Esse novo elemento na sala de aula e na escola pode ser incorporado às práticas pedagógicas 
existentes, ou pode provocar novos movimentos, tanto com relação ao ensinar e aprender, como com relação às trocas interindividuais.

Nesta pesquisa, buscamos conhecer os mecanismos sociocognitivos dos sujeitos e como ocorreram as trocas interindividuais nos diferentes contextos de aprendizagem, com o uso do laptop. Assim, ao considerarmos a presença do artefato na sala de aula, nasceu o objetivo da pesquisa: compreender os mecanismos sociocognitivos presentes nas trocas interindividuais dos estudantes nos diferentes contextos de aprendizagem que fazem uso do laptop educacional.

A investigação é de caráter exploratório, em que o delineamento metodológico é dado pelo estudo de caso e se apóia na abordagem teórica da epistemologia genética de Jean Piaget, a qual embasa e se insere na metodologia adotada. Yin (2001, p. 18) considera o estudo de caso como uma estratégia particularmente apropriada quando "se colocam questões do tipo 'como' e 'por que', quando o pesquisador tem pouco controle sobre os eventos e quando o foco se encontra em fenômenos mais contemporâneos inseridos em algum contexto da vida real." Nessa perspectiva, o estudo de caso pode ser uma forma de considerar os elementos para examinar o todo, integrando as partes, com a possibilidade de diferentes registros, como, por exemplo, observações, entrevistas, recursos digitais, como o BlogQuest, anotações no diário de bordo, entre outros elementos presentes nesse processo investigativo.

A pesquisa aconteceu em uma escola da rede pública municipal, situada na região nordeste do Rio Grande do Sul, ao sul do Brasil. É uma instituição com a clientela de crianças e jovens de classe média, provenientes dos bairros próximos da escola. Conta com 450 alunos e 50 professores e atende desde a educação infantil até a educação de jovens e adultos (EJA). O estudo aconteceu com um grupo do sétimo ano, nas aulas da disciplina de História. Essa turma contava com 31 estudantes, dentre os quais escolhemos um grupo para o estudo de caso. Os sujeitos da pesquisa constituíram um grupo de quatro estudantes, de 13 anos, composto por três meninos e uma menina, cujos pais aceitaram que seus filhos participassem da pesquisa e após os esclarecimentos assinaram o termo de consentimento livre e esclarecido. Os personagens da história de Ziraldo - "A 
professora Maluquinha" - inspiraram os nomes fictícios que os sujeitos receberam: Maluquinho, Carolina, Bocão e Junin.

Para construção dos dados, realizamos três encontros de 50 minutos, totalizando 150 minutos. Dois encontros foram sessões de observações e filmagens e um, encontro de entrevista.

$\mathrm{Na}$ composição do estudo de caso, utilizamos como fontes de evidência para construção dos dados as observações registradas nos diários de campo (DC), as filmagens das aulas e do grupo (TF), as entrevistas gravadas com os estudantes (EG) e o blog (diário da web) da disciplina, que abrigava a proposta de BlogQuest (BQ). Do trabalho com esses dados, emergiram, as duas categorias de análise, que denominamos, neste estudo, de cenários: Contextos de Aprendizagem e Processos Sociocognitivos. Nosso foco, aqui, está na categoria Processos Sociocognitivos.

\section{Resultados e discussão}

Com base na organização dos dados, construímos a categoria de análise Processos Sociocognitivos. Esta categoria se constitui a priori, segundo a abordagem teórica adotada, sendo analisadas as interações entre os estudantes. Investigamos as possibilidades de trocas interindividuais oferecidas aos estudantes nas situações de ensino e aprendizagem com a presença do laptop educacional e analisamos como os mecanismos sociocognitivos (coação, conformismo e cooperação) se manifestavam nessas situações.

O Quadro 1 apresenta a organização do movimento de análise, destacando a categoria, as subcategorias e os indicadores. 
Quadro 1 - Categoria, subcategoria e indicadores

\begin{tabular}{|c|c|c|}
\hline $\begin{array}{c}\text { Cenários ou } \\
\text { Categorias }\end{array}$ & $\begin{array}{c}\text { Cenas ou } \\
\text { Subcategorias }\end{array}$ & $\begin{array}{l}\text { Roteiro ou } \\
\text { Indicadores }\end{array}$ \\
\hline \multirow{3}{*}{$\begin{array}{l}\text { Mecanismos } \\
\text { Sociocognitivos }\end{array}$} & Coação & $\begin{array}{l}\text { Respeito unilateral } \\
\text { Heteronomia } \\
\text { Regras externas ao sujeito } \\
\text { Hierarquia nas relações }\end{array}$ \\
\hline & Conformismo & $\begin{array}{l}\text { Respeito unilateral } \\
\text { Hierarquia nas relações } \\
\text { Heteronomia } \\
\text { Não envolvimento ou comprometimento }\end{array}$ \\
\hline & Cooperação & $\begin{array}{l}\text { Descentração } \\
\text { Reciprocidade } \\
\text { Autonomia } \\
\text { Trocas heterárquicas } \\
\text { Respeito mútuo }\end{array}$ \\
\hline
\end{tabular}

Fonte: da autora

Para identificarmos como a categoria Processos Sociocognitivos evidenciou seus movimentos, buscamos nas fontes das situações de aprendizagem pistas das cenas, ou seja, conformismo, coação e cooperação. Estes conceitos se apresentaram de forma sutil nas interações, e nos debruçamos sobre os conceitos piagetianos para que fosse possível reconhecer os movimentos dos mecanismos sociocognitivos nas trocas interindividuais dos estudantes.

No estudo, evidenciamos a prevalência de movimentos de conformismo nas trocas entre os estudantes. Identificamos o sentimento de desigualdade entre o que respeita e o que é respeitado, evidenciando, assim, o respeito unilateral. O recorte de um momento da entrevista evidencia esse movimento: 
PESQUISADORA - E como é que vocês chegaram a escolher esses desenhos?

CAROLINA - Eu que escolhi esses desenhos.

MALUQUINHO - Não sei se foi a profe ou a Carolina que falou em fazer da Rua do Ouvidor.

CAROLINA - Fui eu! A gente optou por essa imagem.

PESQUISADORA - Quem mais argumentou na escolha, quem defendeu sua ideia?

MALUQUINHO - Foi a Carolina.

Essa posição poderia estar baseada em uma relação de pressão de um dos componentes sobre o grupo, fazendo com que prevalecesse seu ponto de vista. Ao mesmo tempo, o grupo, ao aceitar a decisão de Carolina, pode estar evidenciando o aspecto de autoridade da colega ou o de conformismo intelectual do grupo com relação à decisão tomada.

Nesse movimento, podemos identificar uma relação de conformismo intelectual, ou seja, uma valorização não-recíproca do outro, o que leva a uma submissão voluntária. Manifestou-se um falso equilíbrio nessa troca, pois prevaleceu o ponto de vista da Carolina, fazendo com que o seu pensar, a sua escolha fosse a verdadeira, não havendo reciprocidade. Evidenciamos, assim, um falso equilíbrio na troca, visto que não houve reversibilidade do pensamento. Dessa forma, além da ausência de questionamento pelos colegas, encontramos uma noção equivocada de relação de reciprocidade tanto de Carolina, que se mantém na condição de egocentrismo intelectual, quanto dos colegas, que se colocam numa condição de conformismo.

Percebemos, a partir dos dados da entrevista e das informações sobre as normas da escola sobre o uso do laptop educacional, evidências de regras coercitivas, características normalmente oriundas do respeito unilateral, como, por exemplo, a regra estabelecida pela escola: "Não entrar em sala de bate-papo".

Esta regra foi imposta pela equipe diretiva ou pelos educadores, figuras que representam autoridade no contexto escolar. A regra foi construída pelo corpo docente da escola, de forma unilateral, proibindo o acesso às redes sociais e aos comunicadores 
instantâneos do laptop educacional. No entanto, há um duplo movimento, um movimento coercitivo por parte da escola e uma falsa acomodação dos estudantes. Talvez a aceitação da regra tivesse acontecido em algum momento, mas, agora, há movimentos de rompimento dessa regra. Identificamos que, mesmo ela existindo, há relatos de trocas de mensagens para discutir questões relativas à proposta de trabalho fora da escola e na própria escola. Flagramos essa situação do "é proibido", quando:

[...] o nosso personagem Junim, ao finalizarmos nossa filmagem, estava com o ícone aberto do comunicador instantâneo em sua barra de tarefas e estava conversando com os colegas da escola que também se encontravam online. Segundo Junim, eles ficam conversando sobre o que estavam fazendo em aula (Anotações do DP).

Nesse movimento, fizemos uma analogia das conversas paralelas que acontecem na sala de aula, com as conversas que se manifestavam "silenciosamente" na interface digital. Os nossos personagens transgridem a regra imposta, porque essa não foi construída de forma cooperativa. Desse modo, os dados parecem indicar que o ambiente escolar influencia na forma como o sujeito resolve seus conflitos. O respeito unilateral certamente leva à regra coercitiva. Neste caso, portanto, num primeiro momento, era preciso se conformar com as regras, pois era obrigatória, tendo origem na autoridade que a escola representa. Desse respeito unilateral, então, resultam regras externas ao estudante, ou seja, heterônomas.

Na verdade, a coação faz com que deixemos de participar potencialmente da construção de regras coletivas, inibindo, assim, o respeito mútuo, o qual, segundo Piaget (1977), é gerador de relações cooperativas. Para que os estudantes internalizem as regras, é importante que possam construí-las cooperativamente, por mjeio de sua interação com o grupo social.

Quando vivenciamos e praticamos as regras de acordo com a cooperação, as reelaboramos e aplicamos em nossa vida, compreendendo que elas podem ser mutáveis. Dessa maneira, podemos ser capazes de respeitá-las sem necessidade de coação, porque conseguimos sair do nosso ponto de vista. 
Para Piaget (1977 e 1973), não conseguimos cooperar sem passar pela coação, porque essa fase é também parte do desenvolvimento humano. Assim, é importante reconhecer em que fase do desenvolvimento moral está nosso estudante para que possamos intervir, com o sentido de apoiar a saída da condição de heteronomia para a cooperação. É próprio da condição humana fazer o trajeto pela anomia, a ausência de normas, passar pela heteronomia, as normas impostas, e adentrar na autonomia, a criação cooperativa das normas.

Compreendemos que essa passagem precisa estar envolta por oportunidades do exercício cooperativo. Entretanto, ainda temos a coação como prerrogativa nas trocas, como demonstra o recorte:

Carolina comenta: "Bolei o que a gente ia fazer, mandei um e-mail pro Bocão, falando pra ele o que ele tinha que desenhar. Só que ele não desenhou. Aí a gente resolveu vir na escola na quarta, eu falei pra eles mais ou menos as tarefas, o que tinha que desenhar e pesquisar na internet. O Maluquinho tinha desenhado a praia do Rio de Janeiro e o Bocão pintou, pesquisei mais uma imagem e daí cada um fez mais uma" (Transcrição da EG).

No caso em especial, a coação se apresenta entre os seus pares, prevalecendo a relação heteronômica, de dependência da colega, e de uma relação hierárquica, na qual a situação não permite que as trocas interindividuais ocorram, que o outro manifeste e explore seu pensar com o grupo, propondo outras alternativas. Do mesmo modo que os colegas aceitam passivamente o posicionamento da Carolina, deparam com as regras já estabelecidas, acionando o mecanismo de conformismo, porque preferiam não confrontar suas incertezas com as certezas dos companheiros de grupo.

Nesse sentido, a relação de conformismo está condicionada a uma atitude de respeito unilateral, o que, para Piaget (1977), envolve o conceito de estima, isto é, a relação está baseada no medo de perder o seu valor perante o sujeito pelo qual tem admiração. Assim, a coação evidenciada se manifesta numa relação entre os seus pares, que se fortaleceu por meio da autoridade ou do prestígio. 
No recorte analisado, não ocorreu, entre os estudantes, troca de pontos de vista; a decisão foi simplesmente aceita como absoluta. Logo, podemos dizer que houve um desequilíbrio nas trocas interindividuais devido ao egocentrismo intelectual, pois não se viabilizou a coordenação de pontos de vista entre os sujeitos na interação.

Percebemos que a relação autoritária entre pares prevaleceu sobre a relação cooperativa, embora o grupo se apresentasse em um estágio operatório-formal (PIAGET, 1977), em que se consegue pensar abstratamente, começando a perceber os diferentes pontos de vista para se chegar a uma conclusão comum.

Durante a investigação, supúnhamos encontrar entre os estudantes esse movimento, em que sua formação estivesse comprometida com o desenvolvimento da autonomia, de sujeitos fortalecidos na sua individualidade, como participantes responsáveis no grupo, no qual fossem ativos, capazes de produzir o seu saber e problematizar questões, a fim de fortalecer as relações interpessoais (RANGEL, 1992). Essas relações seriam fortificadas por meio do exercício de respeito mútuo, das vivências solidárias e cooperativas.

Ressaltamos que a autonomia moral é indissociável da autonomia intelectual, porque educar constitui um todo indissociável, e não formamos seres autônomos no domínio moral se:

[...] o indivíduo é submetido a um constrangimento intelectual de tal ordem que tenha que se limitar a aprender por imposição, seja de professores ou colegas, sem descobrir por si mesmo a verdade: se é passivo intelectualmente, não conseguirá ser livre moralmente (PIAGET, 1974, p. 63).

O constrangimento pode ocorrer entre os seus pares, desencadeando um mecanismo de coação entre eles. Nas suas trocas interindividuais, passam a exercer a autoridade de uns sobre os outros, provocando um desequilíbrio das trocas. No entanto, quando o estudante vai confrontando seu ponto de vista com seus pares, há um equilíbrio nas trocas, favorecendo uma reflexão sobre seu próprio pensar. Ao buscar um maior refinamento desse pensar, passa a construir argumentos mais sólidos e complexos, desencadeando um movimento cognitivo de novas equilibrações. 
Entretanto, ao perceber o conformismo entre pares, que aceitam a definição da colega, não havendo movimentos na perspectiva de uma nova equilibração, somos levados a questionar o papel dos educadores na formação de uma autonomia intelectual e moral, na qual devem prevalecer relações solidárias.

Considerando a opinião de Rangel (1992), a maior função da escola deveria ser a educação para o desenvolvimento da autonomia. Contudo, esquecemos que a autonomia é uma meta, pois deveríamos trabalhar para esse fim. Também concordamos com Rangel (1992, p. 83) quando ela aponta que "o que torna legítimo um ato autônomo são as relações de reciprocidade, explicitadas em personalidades que se respeitam mutuamente."

Em algumas situações, percebemos que, para serem aceitos, alguns estudantes adotam uma atitude de submissão, aceitam as regras do outro, enquanto que outros se mostram ativos e argumentativos, para fazerem valer as suas opiniões. O conformismo impede a inovação, o cumprimento de vontade própria, adotando um comportamento de desinteresse, refletido na coesão do grupo. Para complementar o que estamos falando, encontramos outros elementos na fala do grupo sobre a necessidade de evitar o confronto:

\footnotetext{
PESQUISADORA - E quando um não gosta, como é que se faz?

BOCÃO - A gente faz votação, ou é um bate-boca.

PESQUISADORA - Como é o bate-boca?

MALUQUINHO - Geralmente, aqui, nós concordamos.

PESQUISADORA - E sempre concordam?

CAROLINA - Sim, pra gente não ficar discutindo, senão sempre dá briga! E acaba um se emburrando com o outro. Então a gente prefere a paz (Transcrição EG).
}

O recorte acima apresenta uma situação em que há o discurso do conformar-se, de não ir contra a posição do outro. O respeito unilateral próprio do conformismo não manifesta uma troca equilibrada, como já mencionamos. Não percebemos a tentativa de sair da condição de dependência, de moral heterônoma. Essa moral corresponde à responsabilidade objetiva que, segundo Piaget (1977), consiste no momento em que o 
indivíduo julga os atos pelas suas consequências e não por sua intenção; o "bem é o que está de acordo, o mal, o que não está de acordo com as ordens" (PIAGET, 1977, p. 288).

À margem dessa moral, encontramos, pouco a pouco, a moral autônoma, que tem por "princípio a solidariedade, que acentua a autonomia da consciência, a intencionalidade e, por consequência, a responsabilidade subjetiva" (PIAGET, 1977, p. 288).

Assim sendo, o estudante vai, aos poucos, fazendo o movimento de descentralização de seu egocentrismo, começando a perceber a intencionalidade dos atos. Dessa forma, estabelece a tomada de consciência sobre a forma como as regras são construídas e percebe que essa não é imutável.

A partir desse entendimento, nasce um sentimento de respeito às próprias opiniões e às de seus pares, rompendo com o conformismo e com as regras preestabelecidas, impostas a ele, iniciando o movimento argumentativo. Mas, para que esse movimento ocorra, é necessário provocar situações em que haja abertura para a construção de trocas interindividuais equilibradas, num movimento de cooperação intelectual.

O que sintetiza a fala de Piaget sobre o cooperar é o fato de que esse somente nasce pela discussão, e a discussão só é possível entre iguais, "portanto, só a cooperação realizará o que a coação intelectual é incapaz de realizar" (PIAGET, 1977, p. 298). Dito de outra maneira: "Cada um tem a capacidade de inovar, mas na medida em que consegue fazer-se compreender pelos outros e compreendê-los" (PIAGET, 1977, p. 298). De certa forma, somente abandonando a moral heterônoma e seu egocentrismo é que poderemos alcançar a moral autônoma e uma consciência do seu papel na moral no grupo.

Tudo isso nos leva a considerar a fala de Piaget (1977) de que, gradativamente, vamos estabelecendo entre nossos pares uma necessidade de cooperação, direcionando as ações para o respeito mútuo, percebendo a importância e a necessidade de cooperar. Consideramos, aqui, cooperar no sentido piagetiano, em que "cooperar na ação é operar em comum." (PIAGET, 1973, p. 105). 
Importante destacarmos a diferenciação do que entendemos por colaboração e cooperação. A cooperação, diferentemente da colaboração, é um processo de criação de realidades novas, num movimento de equilíbrio das trocas. Já na colaboração, mesmo que nela ocorram as trocas de pensamento, seja por comunicação verbal ou coordenações de pontos de vista, não se evidenciam equilíbrios nas operações cognitivas.

$\mathrm{Na}$ concepção piagetiana, a cooperação realiza-se a partir de três condições necessárias e suficientes: escala comum de valores, conservação dos acordos e reciprocidade entre interagentes. Somente na cooperação ocorre o equilíbrio na troca, mas, para que se atinja esse estado, é fundamental que haja uma relação de igualdade e reciprocidade entre os integrantes, diferentemente da coação ou do conformismo.

Comparativamente, inferimos que a colaboração representa uma etapa das trocas sociais anterior à cooperação, uma caminhada para autonomia, que tem a sua essência baseada na capacidade de tomarmos decisões por nós mesmos. Porém, autonomia não é a mesma coisa que liberdade total. Ser autônomo:

significa ser capaz de considerar os fatores relevantes para decidir qual deve ser o melhor caminho da ação. Não pode haver moralidade quando alguém considera somente $\mathrm{o}$ seu ponto de vista. Se também consideramos o ponto de vista das outras pessoas, veremos que não somos livres para mentir, quebrar promessas ou agir irrefletidamente (KAMII, 1991, p. 31).

A cooperação caracteriza-se pela igualdade, possibilidade de abrir-se ao diálogo, coordenação de pontos de vista diferentes, operações de correspondência, reciprocidade ou complementaridade e pela existência de regras autônomas de condutas fundamentadas de respeito mútuo (PIAGET, 1977).

No nosso estudo, selecionamos um evento que se aproxima do movimento cooperativo entre os estudantes. Nessa situação, encontramos uma aproximação do que citamos sobre o colaborar, considerando que Piaget (1973) distingue o cooperar do colaborar. 


\begin{abstract}
Maluquinho contou como fizeram a seleção dos desenhos que compuseram o cenário do vídeo, acrescentando que foi combinado na aula anterior e por meio do e-mail. Relata que o colega Junim devia ter trazido o desenho já pronto para essa aula. E como esse não o fez, pesquisaram na internet como era a Rua do Ouvidor, no Segundo Reinado, e escolheram a imagem da casa. Ao mesmo tempo, Bocão fala: "Daí eu fiz o desenho. Sou bom em desenho" (Anotações DP).
\end{abstract}

Podemos pensar que o fato de terem feito a combinação das tarefas que cada integrante deveria realizar configura um processo de cooperação, no sentido de que havia uma escala comum de valores, um acordo a fim de chegarem ao objetivo comum, ao mesmo tempo em que o grupo apresentava uma linguagem comum compartilhada. Apesar de discreta, evidenciamos uma troca interindividual equilibrada no momento em que Carolina levou em consideração a argumentação dos colegas. Percebemos, nessa passagem, a reciprocidade, visto que as atitudes foram avaliadas mutuamente.

No entanto, apesar de haver um movimento sutil, este não chega a ser um ato cooperativo, porque não evidenciamos a troca cognitiva, que promove o crescimento intelectual. A cooperação intelectual é condição necessária para o estabelecimento de toda e qualquer troca interindividual equilibrada.

Por outro lado, a escuta ou o fato de considerar o outro, que colhemos nas entrelinhas, tende mais a uma atitude conformista, pois, mesmo considerando a iniciativa de buscar uma solução pelos integrantes e de fazerem uma escolha compartilhada, não houve a reflexão ou discussão. Identificamos que as trocas interindividuais não auxiliaram a passagem do egocentrismo intelectual à cooperação. Encontramos, nessa passagem, o conformismo intelectual, ou seja, embora o grupo tenha presenciado uma escala comum de valores, estes não se conservaram no tempo, o que desencadeou uma submissão voluntária.

O conformismo intelectual, aceito pelo grupo voluntariamente, não favorece a capacidade argumentativa, pois é somente por meio da discussão que o estudante consegue expor seu ponto de vista, justificá-lo e mostrar sua flexibilidade na negociação com os colegas. Dessa forma, a estrutura do diálogo cooperativo se apresenta de forma 
mais complexa do que numa explanação simples, com hierarquia de papéis entre os interagentes.

Já o movimento cooperativo, por sua vez, caracteriza-se pela igualdade, discussão, troca de pontos de vista e respeito mútuo. Nesse recorte da investigação, deparamos com as características do conformismo, pois não há um comprometimento de um dos estudantes. O grupo encontrou um caminho, por meio da tecnologia digital, para buscar o que precisava para a atividade, o que nos remete, mais uma vez, ao movimento colaborativo do grupo; ao ajudar e resolver a situação, estão fazendo pelo outro; o outro aprende a ser dependente, a esperar que solucionem os problemas por ele.

Considerando que os espaços cooperativos influenciam a cooperação, essa somente será possível quando, nas trocas interindividuais, ocorre o respeito mútuo, que se manifesta a partir da convivência entre os grupos, numa exercitação de práticas cooperativas. Além disso, é necessário desenvolver a capacidade de “operar” junto com o outro, construindo e coordenando as suas relações, por meio da descentração e na convivência, considerando leis de reciprocidade (RANGEL, 1992).

Em poucos momentos se reconheceu nesse grupo um movimento sutil que evidencia nova experiência, na qual alguém consegue abrir mão de seu ponto de vista fazendo as trocas necessárias à construção das hipóteses de trabalho para efetivar a realização do produto final.

\section{Considerações finais}

A ideia inicial do estudo era de que encontraríamos o movimento de cooperação nas trocas interindividuais ao considerar a cultura digital, que envolve a cultura da diversidade, da liberdade de fluxos. No entanto, deparamos com um falso equilíbrio de cooperação, considerando-se que as ações dos estudantes estão no campo do colaborar, não alcançando a cooperação no sentido piagetiano. Em algumas situações, percebemos um fazer individual, fragmentado e somente partilhado, não um operar junto, aspecto essencial da troca cooperativa. 
A cooperação nas trocas interindividuais, nesse estudo, ainda é sutil, em detrimento de um sistema que não opera no sentido de favorecer a autonomia intelectual ou moral, por meio da qual se dá a participação responsável do estudante nas tomadas de decisão, estimuladas pelo diálogo e o respeito mútuo. Isso somente seria possível se houvesse um exercício de cooperação progressivo, caracterizado por ações de reciprocidade, de modo que, aos poucos, pudéssemos substituir o "eu" pelo "nós" e as operações individualizadas pela cooperação.

Acreditávamos que uma problematização dos conceitos das tecnologias digitais ou de sua incorporação poderia ter impulsionado uma modificação nas trocas interindividuais dos estudantes e um exercício cooperativo.

Com o estudo de caso, encontramos nos espaços da escola, uma movimentação da cultura digital que, de certa forma, desencadeou uma sutil perturbação nas práticas educativas, mas não o bastante para movimentar trocas cooperativas. Evidenciamos movimentos iniciais de mudanças nas trocas e nas relações. Percebemos um movimento de interferência na relação da escola, mais especificamente da sala de aula, com as aprendizagens em função da presença do laptop. Por outro lado, isso não serviu para consolidar uma autonomia intelectual e moral. Identificamos que o laptop por si só não provoca alterações nas estratégias pedagógicas. Para que isso ocorra, precisamos envolver os estudantes e os professores, a fim de que possam se sentir desafiados em práticas pedagógicas que envolvam trocas cooperativas, solidárias e autônomas, aproximando a escola da cultura digital.

\section{Referências}

ALMEIDA, Maria Elizabeth Biaconcini de. Tecnologias e currículo: trajetórias convergentes ou divergentes? São Paulo: Paulos, 2011. 
BECKER, Fernando. A escola como laboratório e não auditório. Revista do Instituto Humanitas Unisinos. Entrevista por: Márcia Junges e Patricia Fachin. v.8, n.281, nov.2008. Disponível em:

http://www.ihuonline.unisinos.br/index.php?option=com_content\&view=article\&id=2303 $\&$ secao $=281$. Acesso em: 26 jul. 2010.

DELORS, Jacques. Educação: um tesouro a descobrir. São Paulo: Cortez; Brasília: UNESCO/MEC, 1999.

KAMII, Constance. A criança e o número: implicações educacionais da teoria de Piaget para a atuação junto a escolares de 4 a 6 anos. Campinas, SP: Papirus, 1991.

PIAGET, Jean. Estudos sociológicos. Rio de Janeiro: Forense, 1973.

PIAGET, Jean. O juízo moral na criança. 2. ed. São Paulo: Summus Editorial, 1994.

PIAGET, Jean. O nascimento da inteligência na criança. 2. ed. Rio de Janeiro: Zahar, 1977.

PIAGET, Jean. Sobre a pedagogia. São Paulo: Casa do Psicólogo, 1998.

RANGEL, Maria Cristina do Socorro. Educação matemática e a construção do número pela criança: uma experiência em diferentes contextos socioeconômicos. Porto Alegre: Artmed, 1992.

VALENTINI, Carla Beatris; SOARES, Eliana Maria do Sacramento. Aprendizagem em ambientes virtuais: compartilhando ideias e construindo cenários. Caxias do Sul, RS: Educs, 2005.

YIN, Robert K. Estudo de caso: planejamento e métodos. 2. ed. Porto Alegre: Bookman, 2001. 
Recebido em: 28/06/2013 Aprovado em: 26/09/2013

Universidade do Estado de Santa Catarina - UDESC Programa de Pós-Graduação em Educação - PPGE Revista Linhas

Volume 14 - Número 27 - Ano 2013 revistalinhas@gmail.com 